\title{
Atmospheric humidity is unlikely to serve as an important water source for crustose soil lichens in the Tabernas Desert
}

\author{
Giora J. Kidron $^{1 *}$, Rafael Kronenfeld ${ }^{2}$ \\ ${ }^{1}$ Institute of Earth Sciences, The Hebrew University, Givat Ram Campus, Jerusalem 91904, Israel. \\ ${ }^{2}$ Meteorological unit, Israel Meteorological Service, Kibbutz Sede Boqer 84993, Israel. \\ * Corresponding author. Tel.: + 972-544-967-271. Fax:+972-2-566-2581. E-mail: kidron@mail.huji.ac.il
}

\begin{abstract}
Dew is commonly regarded as an important water source for lichens. This is also the case for crustose lichens that are attached to the substrate, whether rocks or soil. While being verified during ample research on rock-dwelling lichens in the Negev, the findings from soil-dwelling lichens (lichen biocrusts) are not conclusive. In the Tabernas Desert, the soil surface is characterized by a lush cover of crustose lichens. These soil biocrusts (biological soil crusts) were reported to use dew for photosynthesis while, at the same time, it was also observed that these crustose chlorolichens are relatively non-wettable. In an attempt to explore the apparent controversy, two year-long meteorological data (minimum air temperature and relative humidity, RH), during which chlorolichens were thought to utilize dew for photosynthesis (2006-2007) were analyzed. The analysis includes a comparison to the meteorological conditions that prevailed in the Negev during 135 days of manual dew measurements. As found for the Negev, net photosynthesis by the chlorolichens is expected once the $\mathrm{RH}$, as measured at the meteorological station, is $\geq 90 \%$ while vapor condensation (dew) is expected once $\mathrm{RH}$ is $\geq 95 \%$. RH in the Negev was substantially higher than the average RH of $75.0-87.2 \%$ registered during the rainless days of 2006-2007 in the Tabernas, implying that RH in the Tabernas is too low to facilitate frequent dew formation and net photosynthesis by the lichens. Photosynthesis in the Tabernas is mainly confined to rainy periods, taking place either due to direct wetting by rain, or following vapor condensation from the subsurface (distillation). Our findings do not support the view that dew is an important water source for the establishment and growth of crustose soil lichens in the Tabernas. Moreover, the low RH in the Tabernas may also imply that dew may only have a very limited role in providing water to lithobionts in this ecosystem.
\end{abstract}

Keywords: Biocrust; Cyanobacteria; Distillation; Lithobionts; Respiration; Negev Desert.

\section{INTRODUCTION}

Covering large areas in arid and semiarid regions, biocrusts (known also as biological soil crusts or microbiotic crusts) play an important role in shaping the ecosystem. They were reported to play an important role in surface stabilization (Jia et al., 2008; Kidron et al., 2017), runoff generation and subsequently water redistribution (Kidron and Yair, 1997; Lázaro et al., 2015), evaporation (Harper and Marble, 1988; Kidron and Tal, 2012; Wang et al., 2007), and organic carbon and nitrogen fixation (Elbert et al., 2012). They were also reported to affect seedling germination (Huang and Gutterman, 1998; Prasse and Bornkamm, 2000) and the growth of vascular plants (Kidron, 2019). Precisely due to their diverse functions, knowledge regarding their water source and growth conditions is of prime importance.

Two possible water sources may be utilized by biocrusts for photosynthesis: meteoric water (rain which either directly wets the biocrusts or indirectly via distillation, i.e., vapor stemming from the wet ground, which the lichens can use either as vapor or upon condensation as liquid water) and atmospheric humidity, i.e., vapor, dew and fog, known also as non-rainfall water (NRW). In addition to rain, dew and fog has long since been considered important water sources for biocrusts, whether cyanobacteria, cyanolichens (lichens with cyanobacteria as photobionts), chlorolichens (lichens with green algae as photobionts) or mosses (Jia et al., 2014; Rodríguez-Caballero et al., 2013; Thomas et al., 2011; Veste et al., 2001; Zhang et al., 2015). This conclusion partly stems from detailed measurements that were principally conducted in the Negev Desert,
Israel, during which high photosynthetic activity was registered for rock-dwelling (lithic) lichens.

In an attempt to observe good utilization of dew and fog by lithic lichens in the Negev, $\mathrm{CO}_{2}$ exchange was measure within a closed chamber in which the interior conditions were controlled in accordance with the exterior (field) conditions (Kappen et al., 1979; Lange et al., 1970a, b). Thus for instance, during 355 days of continuous measurements of the lichen Ramalina maciformis (1972/73), 29 days (8.2\%) were rainy and as expected resulted in a positive $\mathrm{C}$ balance. While the carbon balance was either zero or negative during 88 days $(24.7 \%)$ of the remaining days, the lichen showed a net positive carbon balance during $53.3 \%$ of the days: during 172 dewy and foggy days $(48.5 \%)$ and during additional 17 days (4.8\%) during which the relative humidity was sufficiently high (Kappen et al., 1979). Accordingly, while the net photosynthetic yield may have reached $10 \mathrm{mg} \mathrm{CO}_{2} \mathrm{~g}^{-1} \mathrm{~d}^{-1}$ on rainy days (attributed to daytime long activity and relatively low losses of carbon following respiration under the cool nocturnal conditions), it was up to $3 \mathrm{CO}_{2} \mathrm{~g}^{-1} \mathrm{~d}^{-1}$ during the winter dewy days, and 1-2 $\mathrm{CO}_{2}$ $\mathrm{g}^{-1} \mathrm{~d}^{-1}$ during the warm late summer and fall dewy days. Being frequent, dew was thus regarded as a main water source for the lithic lichens in the Negev, leading many scholars to assume that dew and fog play an important role in the establishment and growth for many arid and semiarid soil biocrusts. This was also the case for the Tabernas Desert.

The Tabernas Desert is located in the semiarid SE Spain, approximately 20-25 km from the Mediterranean Sea (Fig. 1a), and inhabited by a lush cover of soil lichens (Fig. 1b). Dew formation was frequently reported as taking place in the 

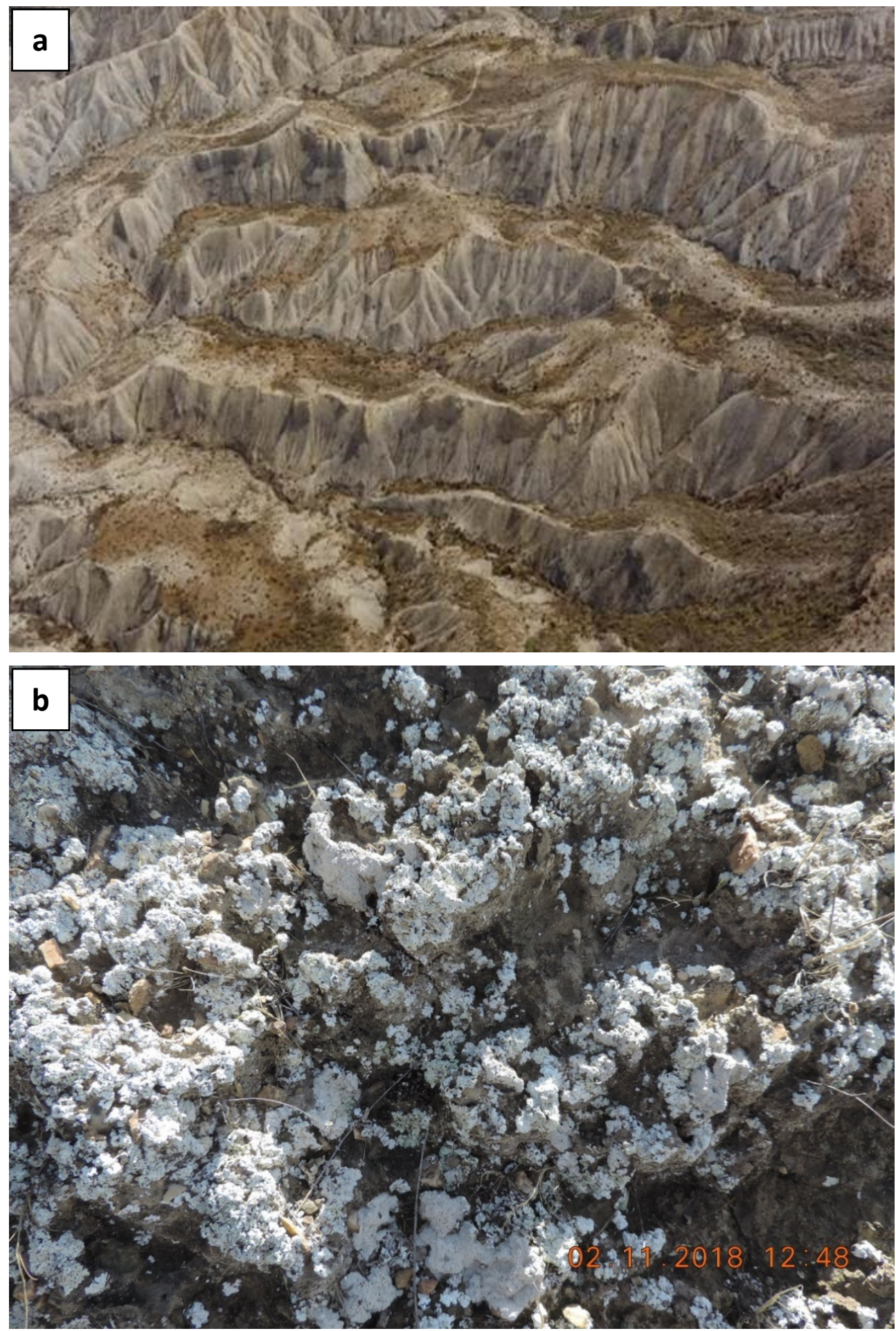

Fig. 1. General view (a) and a close look at the lichen biocrust (mostly Diploschistes diacapsis) at the Tabernas (b). Photographs courtesy of R. Lázaro.

Tabernas and its vicinity (Moro et al., 2007; Uclés et al., 2013, 2016). Although, as recently substantiated, the occurrence of dew in the Tabernas is actually infrequent as compared to the Negev Desert and therefore the Tabernas cannot be considered a dew desert (Kidron and Lázaro, 2020), many reports concluded that dew formation may play an important role as a water provider for this ecosystem. It was therefore assumed that dew will facilitate the survival and growth of many organisms, such as crustose soil lichens (Moro et al., 2007; Pintado et al., 2010), and will facilitate organism survival also during the harsh dry season (Uclés et al., 2016).
Nevertheless, there were also contradictory accounts, which do not comply with the assumption that surface moistening takes place following dew. For instance, Lázaro et al. (2008, p. 263) observe that during dewy mornings, the crustose lichens appear "waterproof", which is in agreement with detailed dew measurements that were conducted in the Negev biocrusts (Kidron and Kronenfeld, 2020a). While biocrust organisms that protrude above the soil surface, such as mosses, were found to utilize dew in the Negev, the contribution of dew to cyanobacteria or crustose lichens was found to be negligible (Kidron et al., 2002). It was postulated that either the amount is insuffi- 
cient to allow for photosynthesis or that daytime photosynthesis is too short to compensate for the nocturnal carbon loss during nocturnal respiration, subsequently resulting in a negative carbon balance (Kidron and Starinsky, 2019; Kidron and Kronenfeld, 2020a).

The current research explores the absence of photosynthesis during certain summer months in the Tabernas (Pintado et al., 2010 ), and the apparent overestimation of the dew values reported by Uclés et al. $(2013,2016)$ from the Tabernas and/or its vicinity. According to Kidron and Kronenfeld (2017, 2020b), microlysimeters (MLs), used by Uclés et al. $(2013,2016)$ tend to overestimate the amount of dew and may therefore be unreliable in the assessment of the dew regime. It was argued that the air gap in between the two walls of the ML enhances nocturnal cooling (similarly to a loose cobble undergoing enhanced cooling in comparison to bedrock), subsequently overestimating the actual dew amounts formed on the soil surface. This implies that the amounts of dew capable of forming on the thalli of the crustose lichen may not be as high as reported, and may subsequently result in insufficient moisture to allow for lichen activation.

We propose that previously published values by Pintado et al. (2010) during 2006 and 2007 may have been erroneously attributed to dew, and that the published values of photosynthesis mainly reflect meteoric (rain) water (direct wetting by rain or distillation) rather than dew. In order to determine whether these values from the Tabernas reflect dew or rain we analyzed the meteorological data from 2006 and 2007 and undertook a comparison between this data from the Tabernas and the dew regime in a typical dew desert, the Negev Desert.

\section{METHODOLOGY}

\subsection{The research site and previous measurements}

The Tabernas Desert lies within the Rioja-Tabernas basin ( 200-800 m above msl). It is formed by a series of parallel catchments on deeply dissected Toronian mudstone of marine origin, surrounded by high mountains, $\sim 1400-2000 \mathrm{~m}$ above msl (Fig. 1a). The parent material is mainly composed of $>60 \%$ silt-size gypsum-calcareous and siliceous particles, $20-35 \%$ of fine sand, and $5-10 \%$ of clay (for detailed account see Alexander et al., 2008). Average annual precipitation is $235 \mathrm{~mm}$ (Lázaro et al., 2001), with rain falling principally in fall and winter (40-50 rainy days, with an average of 36 rain events of $>1 \mathrm{~mm}$ ). Average annual temperature is $18^{\circ} \mathrm{C}$; daily average maximum temperatures during the hottest and coldest months are $34.5^{\circ} \mathrm{C}$ and $17.5^{\circ} \mathrm{C}$, respectively, whereas the average of daily minimums are $19.5^{\circ} \mathrm{C}$ and $4^{\circ} \mathrm{C}$ for the hottest and coldest month, respectively (Lázaro et al., 2000, 2001, 2004).

Biocrusts cover two thirds of the surface, mostly in between low-density (10-30\%) shrubs and perennial grass, with the remaining surface exhibiting intense erosion (Cantón et al, 2004; Lázaro et al., 2001). Lichen and cyanobacterial crusts abound. Cyanobacterial biocrusts (dominated by Microcoleus sp.), accompanied by crustose lichens such as Collema spp., Endocarpon pusillum, and Fulgensia spp., mainly occupy the sun-exposed habitats (Miralles et al., 2012). A dark-coloured chlorolichen biocrust, dominated by Psora decipiens, also occupies the relatively sun-exposed habitats (gently sloping north-facing slopes). A whitish-coloured chlorolichen dominated biocrust with Squamarina lentigera and Diploschistes diacapsis (sometimes accompanied by Buellia zoharyi) predominates (Fig. 1b). This crust, mainly confined to the stable northfacing slopes, represents the late-successional stage of biocrusts at the site (Lázaro et al., 2008). Cyanolichens, such as Collema sp., are also present, but less abundant than chlorolichens.
Measurements of photosynthesis that were conducted in the Tabernas during 2006 and 2007 by Pintado et al. (2010) are used for the current analysis. These measurements were conducted on the predominant 1-3 mm thick crustose lichen in the Tabernas, Diploschistes diacapsis. Measurements included the maximum fluorescence emitted by the lichens using a pulse amplitude modulated fluorometer (Minipam, Walz, Germany), with the fiber-optic probe permanently fixed to the ground pointing at the sample lichen. A modulated inciting low red light was used to measure Ft fluorescence followed by saturating pulse $\left(8000 \mu \mathrm{mol}\right.$ photon $\left.\mathrm{m}^{-2} \mathrm{~s}^{-1}\right)$ that allow for the determination of the maximal fluorescence, Fm'. The effective PSII quantum yield was then calculated as $\Delta \mathrm{F} / \mathrm{Fm}$, where $\Delta \mathrm{F}=$ Fm'-Ft (Schreiber, 2004). The values (referred hereafter as photosynthesis) were automatically recorded (at $0.5 \mathrm{~h}$ interval) and stored in a data logger. A positive PSII indicated that the lichen is active and hydrated.

The published results showed high variability. Figure $2 a, 2 b$ and $2 \mathrm{c}$ show the amount of rainy days, the amount of rain, and the monthly number of hours of daylight photosynthetic activity for the 2006-2007 respectively. Figure 3a, 3b, and 3c show the relationships between the amount of rainy days, the rain amount, and the average monthly RH and the monthly number of hours of daylight photosynthetic activity of the lichens, respectively. Whereas no daylight photosynthetic activity was recorded for a total of four months (July and August 2006 and June and July 2007), small or even negligible activity $(<50 \mathrm{~h})$ was recorded for some of the months (March, April, June, September, October and December, 2006 and March, May, August, September and November, 2007). Long activity $(>100 \mathrm{~h}$ ) was recorded during a few months (January and November, 2006 and January and October, 2007), with the remaining months showing intermediate values.

\subsection{Methods}

We conducted an analysis of the meteorological data from the Tabernas during January 2006 until December 2007 from a near-by meteorological station $(8 \mathrm{~km}$ northeast of the town of Tabernas, $37^{\circ} 05^{\prime} 28^{\prime \prime} \mathrm{N} ; 02^{\circ} 18^{\prime} 08^{\prime \prime} \mathrm{W}$, operated by the Andalusian official meteorological unit). The data included the daily rain amount, the relative humidity (RH), and air temperatures (Ta). Our calculations were based on the minimum air temperatures during which the likelihood for vapor condensation is the highest. Td was calculated in accordance with the equation proposed by Lawrence (2005):

$\mathrm{Td}=\mathrm{Ta}-(100-\mathrm{RH} / 5)$

where $\mathrm{Td}=$ dew point temperature $\left({ }^{\circ} \mathrm{C}\right) ; \mathrm{Ta}=$ air temperature $\left({ }^{\circ} \mathrm{C}\right)$ and $\mathrm{RH}=$ relative humidity $(\%)$.

Additionally, and for the sake of comparison, we analyzed dew measurements from Sede Boqer, the Negev Highlands (Israel), and compared them to the relevant meteorological data ( $\mathrm{RH}, \mathrm{Ta}, \mathrm{Td})$ from a nearby meteorological station, $150 \mathrm{~m}$ south of the Sede Boqer site $\left(30^{\circ} 56^{\prime} \mathrm{N} ; 34^{\circ} 23^{\prime} \mathrm{E}\right.$, operated by the Israel Meteorological Service). Assuming that the conditions determining vapor condensation and dew formation are universal (Beysens, 1995; Monteith, 1957), we infer from the climatological condition conducive to dew formation in the Negev that similar conditions might be conducive to dew formation in the Tabernas. Data collected in the Negev Desert is assumed to be reliable also due to the proximity between the meteorological station and the research site where manual dew measurements took place. 

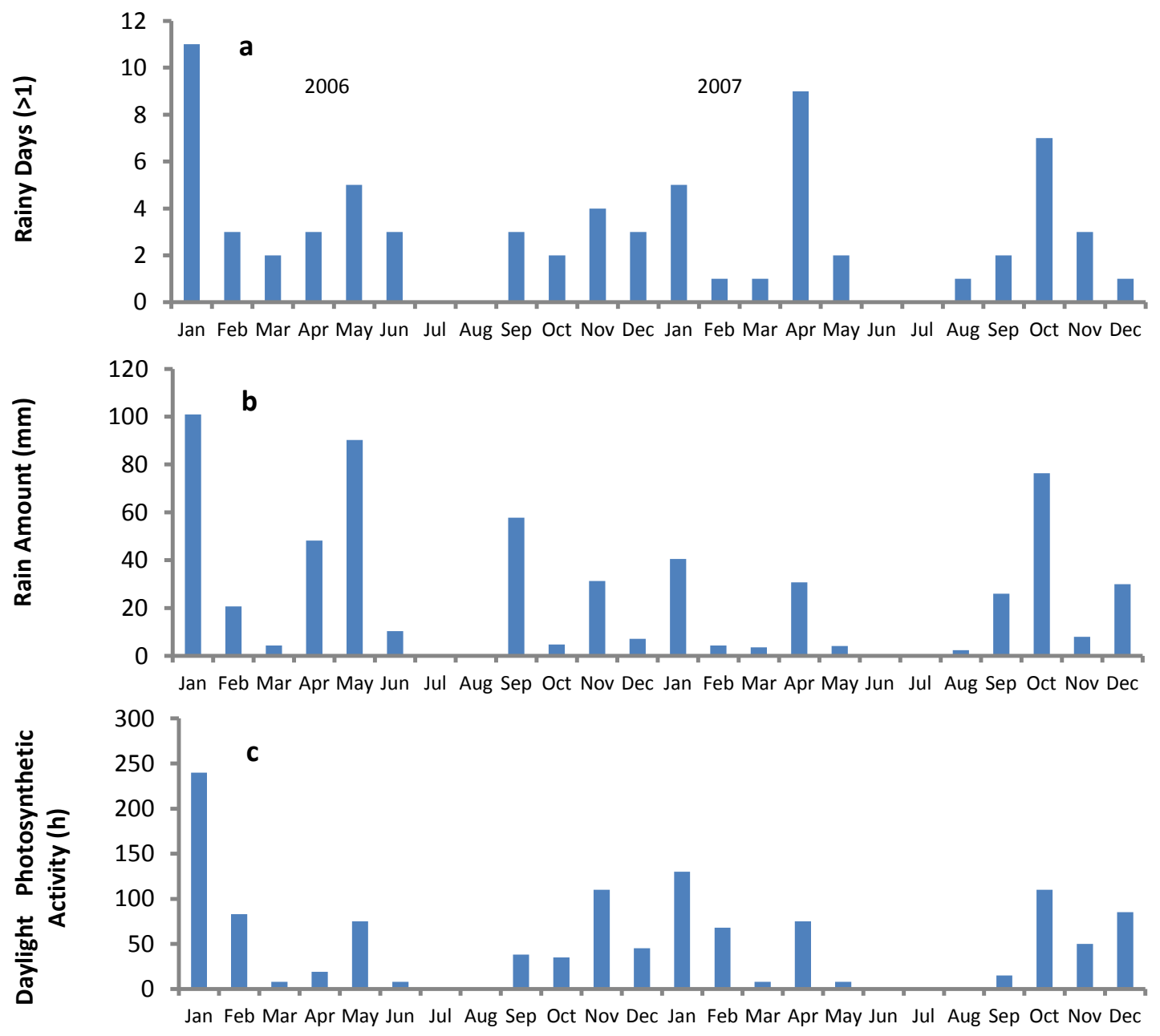

Month

Fig. 2. Monthly amounts of rainy days $>1 \mathrm{~mm}$ (a), rain amount (b) and daylight photosynthetic activity (c) as recorded during 2006 and 2007 (after Pintado et al., 2010).
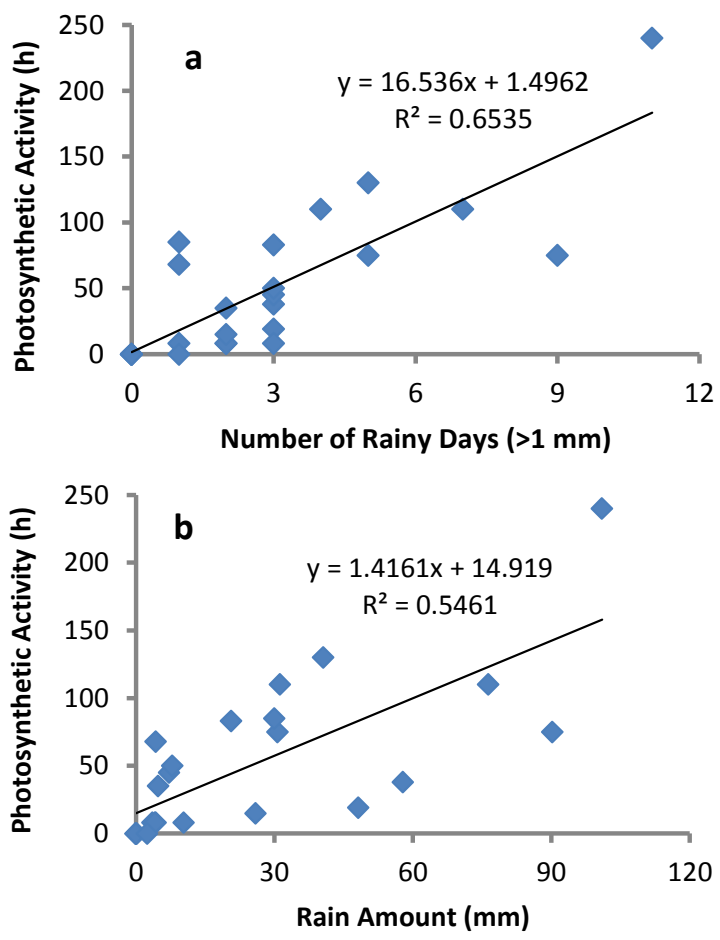

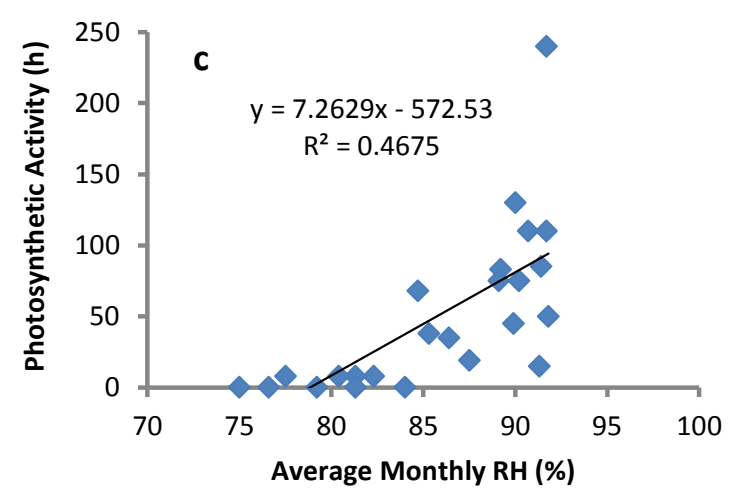

Fig. 3. The relationships between the average monthly daylight photosynthetic activity and the amount of rainy days (a), the amount of rain (b), and the average monthly maximum relative humidity at dawn (c). Data analysis is based on Pintado et al. (2010).

Dew measurements in the Negev were carried out in pairs using the cloth-plate method (CPM). Accordingly, a $6 \times 6 \times$ $0.15 \mathrm{~cm}$ cloth was attached (via adhesive stickers) to the middle of a $10 \times 10 \times 0.2 \mathrm{~cm}$ glass plate overlying a $10 \times 10 \times 0.5 \mathrm{~cm}$ plywood base, forming an identical $0.7 \mathrm{~cm}$-high substrate. The cloths were attached in the late afternoon and collected during 
the early morning of the following day. They were placed into separate flasks, weighed, oven-dried at $70^{\circ} \mathrm{C}$ until completely dried out and reweighed. A total of 135 days of dew measurements were carried out, facilitating a comparison between the dew amounts and the meteorological variables of the adjacent meteorological station.

In addition, measurements that were conducted with cloths directly attached to the soil during the fall of 2009 (using pins) were compared to adjacent cloths attached to the glass plates (CPM). All cloths were concomitantly attached to the surface during the afternoons and concomitantly collected during the following morning as described above.

We are aware of the fact that due to the screen effect of the meteorological station, the $\mathrm{RH}$ and $\mathrm{Ta}$, as measured by the station, may underestimate the values recorded in an unsheltered space outdoors (see also below). Similarly, the actual Td in the field may be slightly lower than that calculated for the meteorological station. Nevertheless, by comparing the outdoor dew values with the data recorded by the meteorological station in the Negev, the relevant threshold for dew formation in the field may be assessed.

\section{RESULTS AND DISCUSSION}

Determining the variable role of different water sources the role of meteoric water or atmospheric humidity - may be difficult. This is all the more so in the Tabernas Desert, where manual measurements are not available and where the rainless period is relatively short, and thus, both water sources may concomitantly play a role in providing water for lichen photosynthesis. A distinction is however possible once the apparent role played by atmospheric humidity is examined during rainless periods.

The data published by Pintado et al. (2010) do not allow for daily analysis, therefore requiring a more crude (monthly) analysis. Accordingly, and once excluding a few days with very low precipitation (June $6^{\text {th }}$ and $14^{\text {th }}, 2006$ with 1.4 and $2.6 \mathrm{~mm}$, respectively, and August $22^{\text {nd }}, 2007$ with $1.7 \mathrm{~mm}$ ), two rainless periods are noted during the 2006-2007 measurement periods: from June $3^{\text {rd }}$ to September $11^{\text {th }}, 2006$ and from June $1^{\text {st }}$ to September $10^{\text {th }}, 2007$ (Fig. 2a, b). In order to evaluate the possible role played by atmospheric humidity (for simplicity, all NRW will be referred hereafter as dew), we focused on the analysis of these periods. These periods (and especially August and September) have relatively clear skies and long nights conducive to dew formation (Veste and Littmann, 2006; Zangvil, 1996), and as such should provide relatively higher dew amounts, as found indeed in many parts of the world (Monteith, 1957; Baier, 1966; Tuller and Chilton, 1973; Zhang et al., 2015), including southeast Spain (Uclés et al., 2015).

Analysis can be undertaken by using the meteorological variables measured at the meteorological station in the Tabernas. Figure $4 \mathrm{a}$ shows the distribution of $\mathrm{RH}$ during the months of June, July, August and the first third of September, as monitored at the meteorological station. As can be noted, a slight increase is apparent from June to September. Yet, the monthly average RH values (75.0-87.2\%) were lower than the values recorded 3-5 days following eight $>10 \mathrm{~mm}$ rain events, which ranged between $75.3-94.5 \%$ (Fig. 4b).

In order to better evaluate the atmospheric conditions conducive for dew formation in the Tabernas, we took advantage of the large amounts of data available from the Negev. In the Negev, dew measurements were principally conducted using the cloth-plate method (CPM). Subsequent measurements were also conducted aiming to study the relationship between the
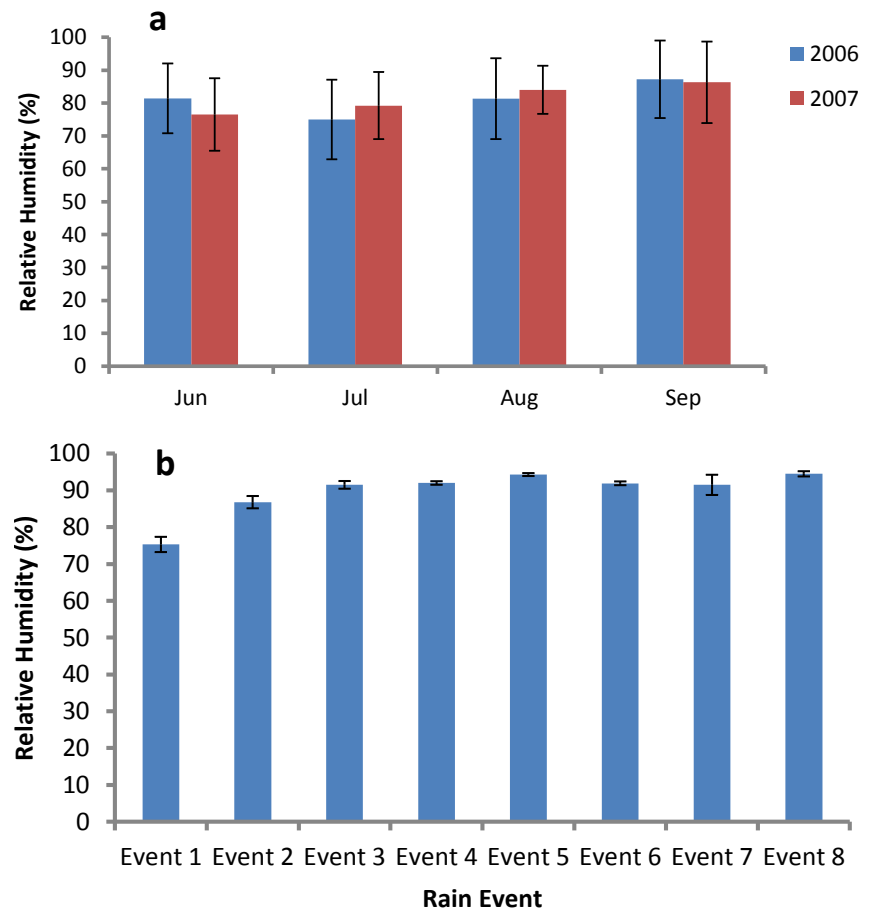

Fig. 4. Average dawn values of RH during the summer rainless period of June $3^{\text {rd }}$ to September $11^{\text {th }}, 2006$, and June $1^{\text {st }}$ to September $10^{\text {th }}$ of 2007 (a), and during 3-5 days following rain events that fell during 8 rainstorms with $\geq 10 \mathrm{~mm}$ during 2006 and 2007 (b). Bars represent one SE. Event $1=45 \mathrm{~mm}$ during 12-14.9.06; event $2=13 \mathrm{~mm}$ during 23.9.06; event $3=10 \mathrm{~mm}$ during 3.11.06; event $4=18 \mathrm{~mm}$ during 7-8.10.06; event $5=20 \mathrm{~mm}$ during 21.9.07; event $6=10 \mathrm{~mm}$ during 3.10 .07 ; event $7=53 \mathrm{~mm}$ during 16-19.10.07; event $8=28 \mathrm{~mm}$ during 26.12.07.

dew formed on the cloths attached to the glass plates to those directly attached to the soil surface. Our analysis was in line with the detailed measurements of dew and lichen photosynthesis in the Negev (Kappen et al., 1979; Lange et al., 1986, 1992) and calculations of the corresponding dew amounts required for net photosynthesis. Accordingly, minimum amounts of 0.05 and $0.1 \mathrm{~mm}$ of dew were found as the thresholds for net photosynthesis of the chlorolichens, and the cyanolichens (or cyanobacteria), respectively (Kidron and Starinsky, 2019).

Figure 5 presents data from long-term periodical measurements in the Negev Highlands (during 2009, 2010, 2014, 2015, 2016, 2018), which include dew values, as measured during 135 days, and the correspondent relative humidity as measured at the adjacent $(\leq 1.5 \mathrm{~km})$ Sede Boqer meteorological station. An important conclusion emerges from Figure 5: the relative humidity at the meteorological station which is required to reach the 0.05 and the $0.1 \mathrm{~mm}$ thresholds in the field are $\sim 90 \%$ and $\sim 95 \%$, respectively. In other words, the amount of vapor that accumulated on the cloths attached to the glass plates reaches $0.05 \mathrm{~mm}$ only once the $\mathrm{RH}$, as measured at the meteorological station, reaches $\sim 90 \%$. Notably, the amounts condensed on the glass plates can be relevant for lithobionts, i.e., cobble-dwelling lichens, as the amounts condensed on the glass plates are similar to those condensed on $10 \mathrm{~cm}$-high licheninhabited cobbles (Kidron, 2000).

The close link between the amounts accumulating on cloths and the lichen thalli (Kidron et al., 2014) implies that under the same conditions during which the cloths and the lichen thalli are attached on the same substrate, the same amount will also accumulate on the lichen thalli. It follows that both substrates (cloths, thalli) reach the same threshold $(0.05 \mathrm{~mm})$ concomitantly. 


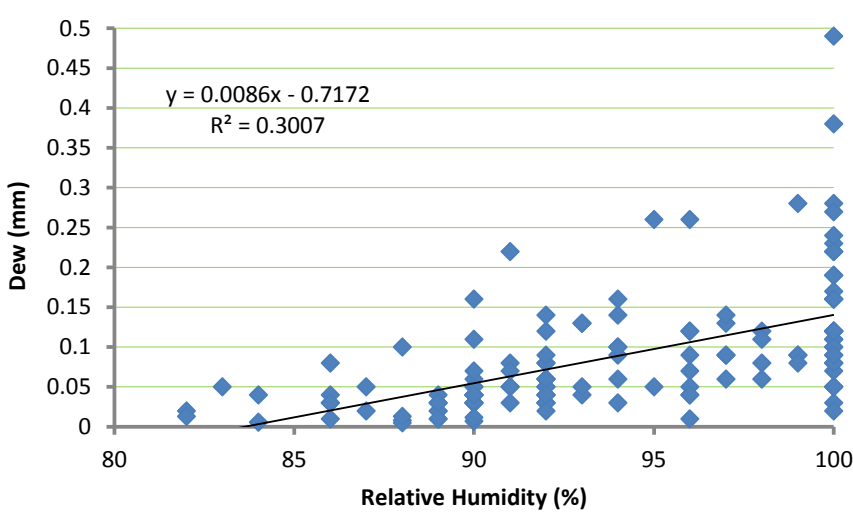

Fig. 5. Long-term relationship $(\mathrm{N}=135$ days) between relative humidity (as measured by a meteorological station) and dew amount (as measured by the CPM) in the Negev Highlands (Sede Boqer). The measurements were carried out periodically during the late summer and fall of 2009, 2010, 2014, 2015, 2016, and 2018.

The threshold for dew formation of $0.1 \mathrm{~mm}$ will be reached only when RH at the meteorological station is $\geq 95 \%$. Since water condensation requires RH of $100 \%$, it implies that once the $\mathrm{RH}$ recorded at the meteorological station reaches $95 \%$, it reaches $100 \%$ on the outdoor glass plate. The lower RH at the meteorological station reflects the slightly warmer conditions within the shielded screen of the meteorological station.

Indeed, following inversion and the lower near-surface wind velocity, minimum air temperatures under outdoor open conditions are lower than that of the meteorological station, entailing that the dew temperature is reached sooner under outdoor conditions. This is shown in Figure 6a in which two-month temperature values (July and August, 2018) that were conducted at and adjacently to a standard $2 \mathrm{~m}$-high meteorological station (Beer Sheva, Israel, $32^{\circ} 00^{\prime} \mathrm{N} ; 34^{\circ} 90^{\prime} \mathrm{E}$,) are presented. These measurements are part of the data collected by the Israel Meteorological Service. On average, near surface minimum temperatures (at $10 \mathrm{~cm}$-height) were $1.2 \mathrm{~K}$ lower (with a range of $0.2-2.5 \mathrm{~K}$ ) than that at the meteorological station. Notably, in comparison to variable heights above surface $(0.7,20,30,40$, $50 \mathrm{~cm}), 10 \mathrm{~cm}$-height glass plates yielded the higher dew amounts (Kidron, 1998). The higher amounts at $10 \mathrm{~cm}$-height above ground in comparison to $0.7 \mathrm{~cm}$-height above ground were explained by the cooler temperatures at this height, which are less impacted by the heat flux emitted from the soil. The higher amounts at $10 \mathrm{~cm}$-height above ground in comparison to 20-50 $\mathrm{cm}$-height above ground were explained by the higher wind velocities at height, which negatively affect the inversion conditions (Kidron, 1998; Kidron et al., 2000).

Concomitant dew measurements conducted during 17 dewy days on cloths attached to glass plates (CPM) and on cloths directly attached (via pins) to the soil surface $(\mathrm{CoS})$ and therefore mimicking crustose soil lichens are shown in Figure 6b. Substantially higher amounts (by a factor of 3.38) were recorded on the glass plates, which reflect the thermal properties of the glass substrate, the isolating effect of the $10 \times 10 \mathrm{~cm}$ plate from the heat flux emitted by the underlying soil, and the higher height (0.7 cm above ground) of the glass plate (Kidron, 1998).

The above data facilitate an analysis of the dew measurements in the Negev Highlands during which dew amounts and dew duration (as determined by half a dozen adjacently placed plates, and the continuous collection of the cloths in $0.5-1 \mathrm{~h}$ intervals during the morning hours) were measured. Figure $7 \mathrm{a}$ shows the relationship between dew amount $(>0.05 \mathrm{~mm})$ and duration (calculated for the CoS by dividing the CPM data by
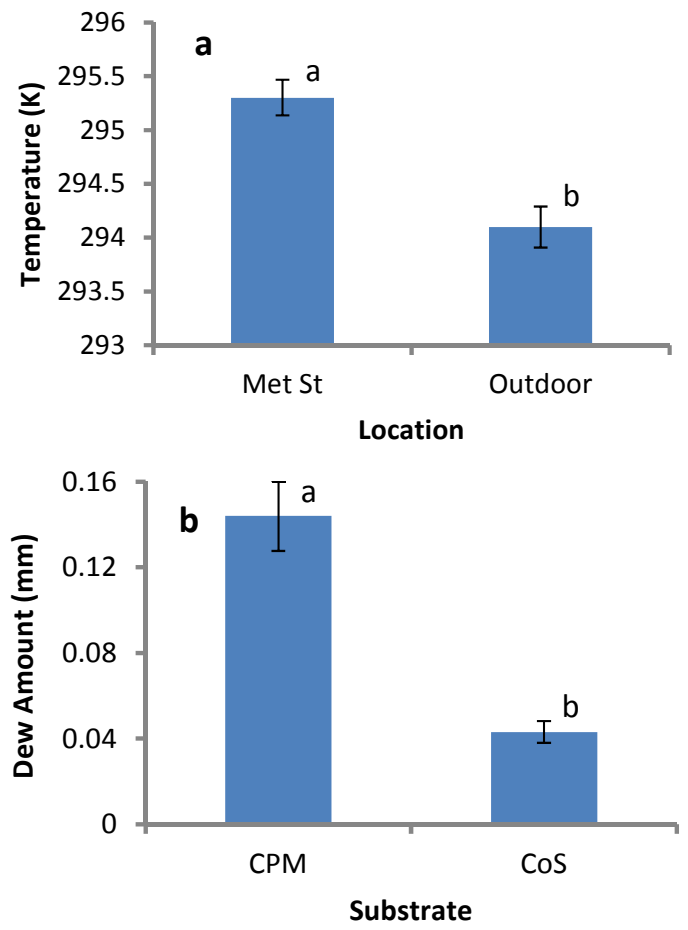

Fig. 6. Concomitant temperature values as measured by the Israeli Meteorological Service within and outdoors at $10 \mathrm{~cm}$-height of the meteorological (Met) station of Beer Sheva during July and August, 2018 (a), and the amount of dew as measured concomitantly during 17 days by CPM (cloths attached to glass plates) and on cloths directly attached to the soil $(\mathrm{CoS})$ in Sede Boqer, Negev Highlands (b). Bars represent one SE. Different letters represent significant differences (paired-t-test; $P<0.05$ ).

3.38) in the Negev (Sede Boqer). Substantially higher amounts and longer duration characterized the CPM, in agreement with previous findings that showed a high correlation between dew amount and duration (Kidron et al., 2000).

Figure $7 \mathrm{~b}$ and $7 \mathrm{c}$ show the relationships between $\mathrm{RH}$ (as measured during these measurement days at the meteorological station) and the calculated dew amount and duration, respectively. As expected, while a relative humidity of $\geq 95 \%$, as measured at the meteorological station, yielded dew amounts of $0.15-0.2 \mathrm{~mm}$ on the glass plates and lasted for $\sim 2.5 \mathrm{~h}$, it corresponded to only $<0.05 \mathrm{~mm}$ of dew lasting for $<1 \mathrm{~h}$ on cloths attached to the soil surface.

The above analysis can be useful for studying the potential conditions for dew formation in the Tabernas. As already indicated above, a relatively low RH was recorded during the rainless periods in the Tabernas (Fig. 4a). Only once RH $>95 \%$ was recorded $\left(95.5 \%\right.$ during July $\left.11^{\text {th }}, 2007\right)$. Similar findings were also found for the rainless months of June, July, August, and September of 2003-2012 in the Tabernas, during which RH $>95 \%$ occurred on average for only 0.9-1.1 days a month (Kidron and Lázaro, 2020). These values imply that dew formation is relatively infrequent.

This conclusion is also supported by calculation of the dewpoint temperatures. According to Beysens (2018), nights during which the differences between the air temperature $(\mathrm{Ta})$ and the dew-point temperature (Td), i.e., Ta-Td are minor have greater likelihood to form dew. In comparison to the Negev during which the differences between $\mathrm{Ta}$ and $\mathrm{Td}$ were minor (1.4, 0.9 and $0.55 \mathrm{~K}$ for dewy days with $0.05,0.06-0.09$ and $\geq 0.10 \mathrm{~mm}$, respectively), the differences between $\mathrm{Ta}$ and $\mathrm{Td}$ for the rainless period of 2006 and 2007 in the Tabernas were 4.0 and $3.9 \mathrm{~K}$, respectively. 

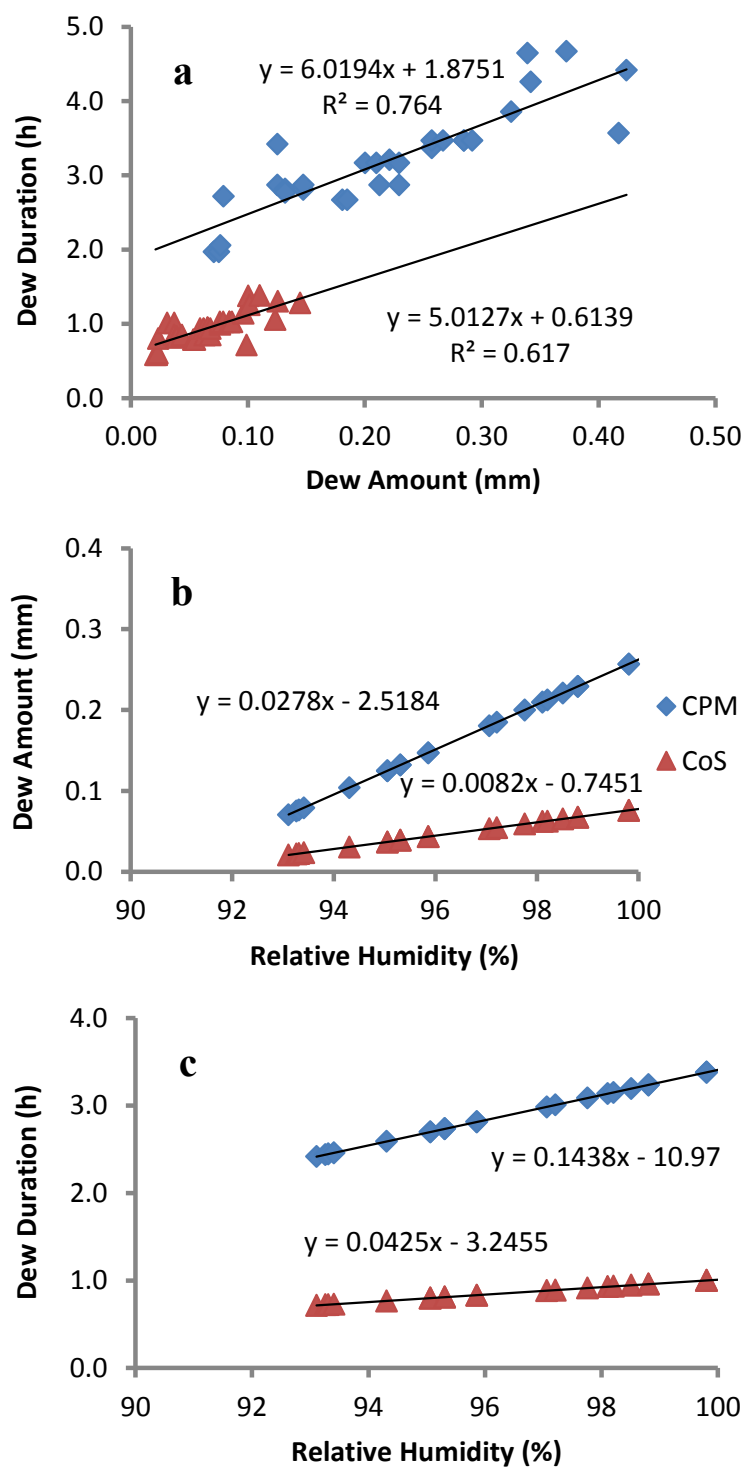

Fig. 7. The relationships between dew amount and duration as measured on the glass plates and calculated for cloths attached to the soil surface (a), and the calculated relationships between the relative humidity and (b) dew amount and (c) duration for cloths attached to the glass plates and the soil surface.

The substantially higher values calculated for the Tabernas may suggest that the likelihood for vapor condensation for the rainless period in the Tabernas is rather low.

With $1.5 \mathrm{~mm}$-thick cloths potentially mimicking $1.5 \mathrm{~mm}$ thick thalli, the analysis presented above may be relevant for lichens. Even for thicker (3 mm-thick) thalli (which corresponds to the maximal thickness of Diploschistes diacapsis), the values will be extremely low. According to Kidron et al. (2002), the dew amount at $3 \mathrm{~mm}$-height is 1.35 times higher than that of the $1.5 \mathrm{~mm}$-height, implying that at $\mathrm{RH}$ of $95 \%$ at the meteorological station, dew at $3 \mathrm{~mm}$-above ground will only reach $0.05 \mathrm{~mm}$ (Fig. $7 \mathrm{~b}$ ), which may only last for $\sim 1 \mathrm{~h}$ (Fig. 7c). Not only does dew amount marginally suffice to activate $3 \mathrm{~mm}$-thick lichens, but activation may not necessarily result in net photosynthesis.

This was verified during detailed photosynthesis measurements. According to Tuba et al. (1996) and Csintalan et al. (2000), the time duration during which dew is available is of paramount importance for the carbon balance. According to these authors, $>2 \mathrm{~h}$ of carbon gain by photosynthesis is required in order to compensate for carbon loss during nocturnal respiration. According to the current calculations, the threshold of $>2 \mathrm{~h}$ of dew duration during the summer months and early fall may only rarely be reached in the Tabernas, implying that the input of atmospheric moisture in the Tabernas is below the necessary threshold required by the lichens to achieve net photosynthesis. And thus, even when occasionally moistened by dew, water availability may not last long enough to allow for a positive carbon balance.

The current analysis supports the data obtained by Pintado et al. (2010) that did not show photosynthetic activity during the rainless months of June, July, August and the first third of September. Yet, it raises doubts regarding the conclusions reached by these authors which considered dew an important water source for lichen photosynthesis during the remaining months. While it is not suggested herein that dew will never result in net photosynthesis, it is argued that it is uncommon and may mainly take place during the rainy season and therefore will not play an important ecological role in the survival of lichens during the rainless season.

The current analysis points therefore to the possibility that meteoric water, rather than dew, may be overwhelmingly responsible for net photosynthesis of the crustose soil lichens in the Tabernas. Thus, the extensive activity of the lichens, as reported by Pintado et al. (2010) during the early morning hours of the rainy season may largely stem from distillation, which mainly takes place due to rain-induced wet ground during the cool morning hours (Monteith, 1957). This conclusion is also supported by the high $\mathrm{RH}$ values recorded after rain (Fig. 4b), and the higher correlation obtained between the amount of rainy days and the monthly photosynthesis of the Tabernas lichens (Fig. 3a).

In this regard it is worth noting that no net photosynthesis was yet reported for crustose soil lichens in the Negev. Photosynthesis by crustose lichens was recorded only once (March $\left.10^{\text {th }}, 1999\right)$ during a rainless morning in the western Negev (Veste et al., 2001). Nevertheless, as indicated by the authors, the time duration was very short, too short to assume net photosynthesis. Similar results were obtained by Wilske et al. (2008) following photosynthetic measurements of crustose lichens in the northern Negev. While net photosynthesis, which characterized the lichens during wet winter days was partially attributed also to dew, no attempt was made to distinguish between dew and distillation, and the results could have reflected distillation, as one may conclude from the negative carbon balance that was obtained during the relatively rainless months of the winter (Wilske et al., 2008). Specifically, as noted by Wilske et al. (2008), no net photosynthesis was recorded even following light rains, a phenomenon attributed to the short duration during which sufficient moisture is present on the soil surface. This was in agreement with the findings reported by Kidron et al. (2002) following $>50$ days of dew measurements in the Negev. These authors reported of only one occasion during which limited moistness following dew took place on the ground, concluding that crustose biocrusts were only rarely wetted by dew.

Our findings do not support the view that dew is an important water source for the establishment and growth of crustose soil lichens in the Tabernas. The data also point to the possibility that the low RH values in the Tabernas may not even suffice to play an important role for rock or cobble dwelling lichens (lithobionts). The lush cover of the soil lichens in the Tabernas may therefore principally stem from rain precipitation (Lázaro, 2004). 


\section{CONCLUSIONS}

By comparing the climatological conditions (air temperatures and relative humidity, RH) during the years 2006 and 2007 in the Tabernas to published data on photosynthetic activity of soil lichens during the same period, it is concluded that dew formation on the crustose soil lichens is relatively unlikely. As found for the Negev Desert during 135 days of manual dew measurements, vapor condensation under unsheltered field conditions requires $\mathrm{RH} \geq 95 \%$ at the meteorological station, while net photosynthesis by the chlorolichens require $\mathrm{RH}$ $\geq 90 \%$. The average $\mathrm{RH}$ values recorded during the rainless months of 2006 and 2007 in the Tabernas were however substantially lower $(75.0-87.2 \%)$, with only a single night during which $\mathrm{RH}>95 \%$ was recorded. The lower $\mathrm{RH}$ values at the Tabernas, coupled with the fact that positive carbon balance is contingent upon the persistence of dew on the ground for $\geq 2 \mathrm{~h}$ under daylight conditions, leads us to conclude that the use of dew by crustose soil lichens for growth in the Tabernas is relatively unlikely. Contrary to previous assumptions, dew (atmospheric humidity) cannot be seen as an important water source for the crustose soil lichens in the Tabernas, which therefore principally rely on rain (meteoric water) for growth.

Acknowledgements. This study was facilitated thanks to Roberto Lázaro, who provided the meteorological data and useful suggestions, and substantially improved the manuscript. His help is greatly acknowledged. The editing by Carol A. Kidron and valuable comments of two anonymous reviewers are highly appreciated.

\section{REFERENCES}

Alexander, R.W., Calvo-Cases, A., Arnau-Rosalén, E., Mather, A.E., Lázaro-Suau, R., 2008. Erosion and stabilization sequences in relation to base level changes in the El Cautivo badlands, SE Spain. Geomorphology, 100, 83-90.

Baier, W., 1966. Studies on dew formation under semi-arid conditions. Agric. Forest Meteorol., 3, 103-112.

Beysens, D., 1995. The formation of dew. Atmos. Res., 39, 215-237.

Beysens, D., 2018. Dew Water. River Publishers, Gistrup, Denmark, $305 \mathrm{p}$

Cantón, Y., Del Barrio, G., Solé-Benrt, A., Lázaro, R., 2004. Topographic controls on the spatial distribution of ground cover in the Tabernas badlands of SE Spain. Catena, 55, 341-365.

Csintalan, Z., Takács, Z., Proctor, M.C.F., Nagy, Z., Tuba, Z., 2000. Early morning photosynthesis of the moss Tortula ruralis following summer dew fall in a Hungarian temperate dry sandy grassland. Plant Ecol., 151, 51-54.

Elbert, W., Weber, B., Burrows, S., Steinkamp, J., Büdel, B., Andrea, M.O., Pöschl, U., 2012. Contribution of cryptogamic covers to the global cycles of carbon and nitrogen. Nat. Geosci., 5, 459-462.

Harper, K.T., Marble, J.R., 1988. A role for nonvascular plants in management of arid and semiarid rangelands. In: Tuller, P.T. (Ed.): Applications of Plant Sciences to Rangeland Management and Inventory. Kluwer, Amsterdam, pp. 135-169.

Huang, Z., Gutterman, Y., 1998. Artemisia monosperma achene germination in sand: effects of sand depth, sand water content, cyanobacterial sand crust and temperature. J. Arid Environ., 38, 27-43.
Jia, R.L., Li, X.R., Liu, L.C., Gao, Y.H., Li, X.J., 2008. Responses of biological soil crusts to sand burial in revegetated area of the Tengger Desert, Northern China. Soil Biol. Biochem., 40, 2827-2834.

Jia, R.L., Li, X.R., Liu, L.C., Pan, Y.X., Gao, Y.H., Wei, Y.P., 2014. Effects of sand burial on dew deposition on moss soil crust in a revegetated area of the Tengger Desert, Northern China. J. Hydrol., 519, 2341-2349.

Kappen, L., Lange, O.L., Schulze, E.-D., Evenari, M., Buschbom, V., 1979. Ecophysiological investigations on lichens of the Negev Desert, IV: Annual course of the photosynthetic production of Ramalina maciformis (Del.) Bory. Flora, 168, 85-105.

Kidron, G.J., 1998. A simple weighing method for dew and fog measurements. Weather, 53, 428-433.

Kidron, G.J., 2000. Dew moisture regime of endolithic and epilithic lichens inhabiting calcareous cobbles and rock outcrops, Negev Desert, Israel. Flora, 195, 146-153.

Kidron, G.J., 2019. The dual effect of sand-covered biocrusts on annual plants: increasing cover but reducing individual plant biomass and fecundity. Catena, 182, 104120.

Kidron, G.J., Kronenfeld, R., 2017. Assessing the effect of micro-lysimeters on NRWI: Do micro-lysimeters adequately represent the water input of natural soil? J. Hydrol., 548, 382-390.

Kidron, G.J., Kronenfeld, R., 2020a. Assessing the likelihood of the soil surface to condense vapor: The Negev experience. Ecohydrology, 2020; e2200.

Kidron, G.J., Kronenfeld, R., 2020b. Microlysimeters overestimate the amount of non-rainfall water - An experimental approach. Catena, 194, 104691.

Kidron G.J., Lázaro, R., 2020. Are coastal deserts necessarily dew deserts? An example from the Tabernas Desert. J. Hydrol. Hydromech., 68, 19-27.

Kidron, G.J., Tal, S.Y., 2012. The effect of biocrusts on evaporation from sand dunes in the Negev Desert. Geoderma, 179-180, 104-112.

Kidron, G.J., Starinsky, A., 2019. Measurements and ecological implications of non-rainfall water in desert ecosystems - a review. Ecohydrology. 2019; e2121.

Kidron, G.J., Yair, A., 1997. Rainfall-runoff relationships over encrusted dune surfaces, Nizzana, Western Negev, Israel. Earth Surf. Process. Landf., 22, 1169-1184.

Kidron, G.J., Herrnstadt, I., Barzilay, E., 2002. The role of dew as a moisture source for sand microbiotic crusts in the Negev Desert, Israel. J. Arid Environ., 52, 517-533.

Kidron, G.J., Starinsky, A., Yaalon, D.H., 2014. Dewless habitat within a dew desert: Implications for weathering and terrestrial evolution. J. Hydrol., 519, 3606-3614.

Kidron, G.J. Yair, A., Danin, A., 2000. Dew variability within a small arid drainage basin in the Negev highlands, Israel. Quart. J. Royal Meteorol. Soc., 126, 63-80.

Kidron, G.J., Ying, W., Starinsky, A., Herzberg, M., 2017. Drought effect on biocrust resilience: High-speed winds result in crust burial and crust rupture and flaking. Sci. Total Environ., 579, 848-859.

Lange, O.L., Schulze, E.D., Koch, W., 1970a. Ecophysiological investigations on lichens of the Negev Desert, II: $\mathrm{CO}_{2}$ gas exchange and water conservation of Ramalina maciformis (Del.) Bory in its natural habitat during the summer dry period. Flora, 159, 38-62.

Lange, O.L., Schulze, E.D., Koch, W., 1970b. Ecophysiological investigations on lichens of the Negev Desert, III: $\mathrm{CO}_{2}$ gas exchange and water metabolism of crustose and foliose li- 
chens in their natural habitat during the summer dry period. Flora, 159, 525-538.

Lange, O.L., Kilian, E., Ziegler, H., 1986. Water vapor uptake and photosynthesis of lichens: performance differences in species with green and blue-green algae as phycobionts. Oecologia, 71, 104-110.

Lange, O.L., Kidron, G.J., Büdel, B., Meyer, A., Kilian, E., Abeliovitch, A., 1992. Taxonomic composition and photosynthetic characteristics of the biological soil crusts covering sand dunes in the Western Negev Desert. Func. Ecol., 6, 519-527.

Lawrence, M.G., 2005. The relationship between relative humidity and the dewpoint temperature in moist air. Bull. Am. Meteorol. Soc., 86, 225-233.

Lázaro, R. 2004. Implications of precipitation on vegetation of water-limited lands. In: Pandalai, S.G. (Ed): Recent Research Development in Environmental Biology, Vol. I. Research Signpost. Kerala (India), pp. 553-591.

Lázaro, R., Alexander, R.W., Puigdefabregas, J., 2000. Cover distribution patterns of lichens, annuals and shrubs in the Tabernas Desert, Almería, Spain. In: Alexander, R.W., Millington, A.C. (Eds.): Vegetation Mapping: from Patch to Planet. Wiley, Chichester, pp. 19-40.

Lázaro, R., Rodríguez-Tamayo, M.L., Ordiales, R., Puigdefábregas, J., 2004. El Clima. In: Mota, J., Cabello, J., Cerrillo, M.I., Rodríguez-Tamayo, M.L. (Eds.): Subdesiertos de Almería: naturaleza de cine. Consejería de Medio Ambiente, Junta de Andalucía. Almería, pp. 63-79.

Lázaro, R., Calvo-Cases, A., Lázaro, A., Molina, I., 2015. Effective run-off flow length over biological soil crusts on silty loam soils in drylands. Hydrol. Process., 29, 2534-2544.

Lázaro, R., Rodrigo, F.S., Gutiérrez, L., Domingo, F., Puigdegabregas, J., 2001. Analysis of 30-year rainfall record (1967-1997) in semi-arid SE Spain for implications on vegetation. J. Arid Environ., 48, 373-395.

Lázaro, R., Cantón, Y., Solé-Benet, A., Bevan, J., Alexander, R., Sancho, L.G., Puigdefabregas, J., 2008. The influence of competition between lichen colonization and erosion on the evolution of soil surfaces in the Tabernas badlands (SE Spain) and its landscape effects. Geomorphology, 102, 252-266.

Miralles, I., Domingo, F., Cantón, Y., Trasar-Cepeda, C., Leirós, M.C., Gil-Sotres, F., 2012. Hydrolas enzyme activities in a successional gradient of biological soil crusts in arid and semi-arid zones. Soil Biol. Biochem., 53, 124-132.

Monteith, J.L., 1957. Dew. Quart. J. Royal Meteorol. Soc., 83, 322-341.

Moro, M.J., Were, A., Villagarcía, L., Cantón, Y., Domingo, F., 2007. Dew measurements by Eddy covariance and wetness sensor in a semiarid ecosystem of SE Spain. J. Hydrol., 335, 295-302.

Pintado, A., Sancho, L.G., Blanquer, J.M., Green, T.G.A., Lázaro, R., 2010. Microclimatic factors and photosynthetic activity of crustose lichens from the semiarid southeast of Spain: long-term measurements for Diploschistes diacapsis. Bibliotheca Lichenologica, 105, 211-224.

Prasse, R., Bornkamm, R., 2000. Effect of microbiotic soil surface crusts of emergence of vascular plants. Plant Ecol., $150,65-75$.
Rodríguez-Caballero, E., Cantón, Y., Chamizo, S., Lázaro, R., Escudero, A., 2013. Soil loss and runoff in semiarid ecosystems: A complex interaction between biological soil crusts, micro-topography, and hydrological drivers. Ecosystems, 16, 529-546.

Schreiber, U., 2004. Pulse-amplitude (PAM) fluorometry saturation pulse method. In: Papageorgiou, G., Govindjee, S. (Eds.): Chlorophyll fluorescence: a signature of photosynthesis. Kluwer Academic Publishers, Dordrecht, The Netherlands, pp. 279-319.

Thomas, A.D., Hoon, S.R., Dougill, A.J., 2011. Soil respiration at five sites along the Kalahari Transect: Effects of temperatures, precipitation pulses and biological soil crust cover. Geoderma, 167-168, 284-294.

Tuba, Z., Csintalan, Z., Proctor, M.C.F., 1996. Photosynthetic responses of a moss, Tortula ruralis, ssp. ruralis, and the lichens Cladonia convoluta and C. furcata to water deficit and short periods of desiccation, and their ecophysiological significance: a baseline study at present-day $\mathrm{CO}_{2}$ concentration. New Phytol., 133, 353-361.

Tuller, S.T., Chilton, R., 1973. The role of dew in the seasonal moisture balance of a summer-dry climate. Agric. Meteorol., $11,135-142$.

Uclés, O., Villagarcía, L., Cantón, Y., Domingo, F., 2013. Microlysimeter station for long term non-rainfall water input and evaporation studies. Agric. Forest Meteorol., 182-183, 13-20.

Uclés, O., Villagarcía, L., Cantón, Y., Lázaro, R., Domingo, F., 2015. Non-rainfall water inputs are controlled by aspect in a semiarid ecosystem. J. Arid Environ., 113, 43-50.

Uclés, O., Villagarcía, L., Cantón, Y., Domingo, F., 2016. Partitioning of non rainfall water input regulated by soil cover type. Catena, 139, 265-270.

Veste, M., Littmann, T., 2006. Dewfall and its geo-ecological implication for biological surface crusts in desert sand dunes (north-western Negev, Israel). J. Arid Land Studies, 16, 139-147.

Veste, M., Littmann, T., Friedrich, H., Breckle, S.-W., 2001. Microclimatic boundary conditions for activity of soil lichen crusts in sand dunes of the north-western Negev desert, Israel. Flora, 196, 465-474.

Wang, X.P., Li, X.R., Xiao, H.L., Berndtsson, R., Pan, Y.X., 2007. Effects of surface characteristics on infiltration patterns in an arid shrub desert. Hydrol. Process., 21, 72-79.

Wilske, B., Burgheimer, J., Karnieli, A., Zaady, E., Andreae, M.O., Yakir, D., Kesselmeir, J., 2008. The $\mathrm{CO}_{2}$ exchange of biological soil crusts in a semiarid grass-shrubland at the northern transition zone of the Negev Desert, Israel. Biogeosci. Discuss., 5, 1969-2001.

Zangvil, A., 1996. Six years of dew observation in the Negev Desert, Israel. J. Arid Environ., 32, 361-372.

Zhang, O., Wang, S., Yang, F.L., Yue, P., Yao, T., Wang, W.Y., 2015. Characteristics of dew formation and distribution, and its contribution to the surface water budget in a semi-arid region in China. Boundary-Layer Meteorol., 154, 317-331.

Received 31 January 2020 Accepted 24 July 2020 